\title{
Magnetic and electrical properties of undoped and holmium doped ZnO thin films grown by sol-gel method
}

\author{
M. Popa ${ }^{1, a}$, G. Schmerber ${ }^{2}$, D. Toloman ${ }^{3}$, M. S. Gabor ${ }^{1}$, A. Mesaros ${ }^{1}$, \\ T. Petrisor ${ }^{1, b}$ \\ ${ }^{1}$ C4S, Technical University, 28 Memorandumului Street, 400114 Cluj-Napoca, Romania \\ 2 IPCMS, UMR 7504 CNRS-UDS, 23 rue du Loess, B.P. 43, 67034 Strasbourg Cedex 2, France \\ ${ }^{3}$ National Institute for Research and Development of Isotopic and Molecular Technologies, \\ 65-103 Donath Street, 400293 Cluj-Napoca, Romania \\ amip3pim@yahoo.com (corresponding author) \\ ${ }^{\mathrm{b}}$ traian.petrisor@phys.utcluj.ro (corresponding author)
}

Keywords: $\mathrm{ZnO}$, holmium, electrical properties, magnetism, thin films.

\begin{abstract}
Undoped and holmium-doped $\mathrm{ZnO}$ thin films were obtained, using the sol-gel method. The films were characterized by scanning electron microscopy (SEM), Hall effect measurements, electron paramagnetic resonance (EPR) spectroscopy and superconducting quantum interference device - vibrating sample magnetometry (SQUID-VSM). The Hall effect measurements have indicated a n-type conduction with a resistivity of about $3.2 \Omega . \mathrm{cm}$ for the undoped $\mathrm{ZnO}$ and of about $4.5 \Omega$.cm for the 5 at. \% Ho-doped $\mathrm{ZnO}$ thin films. The EPR measurements have indicated the presence of interstitial zinc in the undoped $\mathrm{ZnO}$ and the presence of zinc vacancies in 5 at. \% Ho-doped $\mathrm{ZnO}$. Ho (5 at. \%)-doped $\mathrm{ZnO}$ films exhibit superparamagnetism at $5 \mathrm{~K}$, while a low paramagnetic behavior was observed at room temperature.
\end{abstract}

\section{Introduction}

$\mathrm{ZnO}$ is a promising material for many applications such as optoelectronic or spintronic devices, solar cells, transparent conductors, sensors, especially due to its wide direct band gap (3.37 eV) [12]. Lately, ZnO-based diluted magnetic semiconductors (DMSs) have been of great interest because of some theoretical predictions of room temperature ferromagnetism [3]. So far, doping $\mathrm{ZnO}$ with transition metals like $\mathrm{Co}, \mathrm{Fe}, \mathrm{Mn}$, $\mathrm{Ni}$ was usually employed in order to obtain ferromagnetic properties in $\mathrm{ZnO}$ [4-12]. However, the origin of the ferromagnetism is already controversial. Some studies indicate no ferromagnetism in transition metal doped $\mathrm{ZnO}$ [13], while others detected metal clusters in the $\mathrm{ZnO}$ matrix, the origin of the ferromagnetic properties being associated with defects in the $\mathrm{ZnO}$ matrix [14]. According to recent studies, a ferromagnetic behavior has also been observed in some undoped $\mathrm{ZnO}$ samples, as well and was usually attributed to the presence of defects, especially interstitial zinc and oxygen vacancies [15]. Rare earths (RE) doped $\mathrm{ZnO}$ with has also attracted considerable interest due to their $4 \mathrm{f}$ shells [16-21]. The $4 \mathrm{f}$ electrons are localized and the exchange interactions are indirect via conduction electrons, which result in high total magnetic moments per atom owing to its high orbital momentum [16]. Rare earths such as Gd [16, 22-24], Tb [19, 25], Er [17], Eu [26], and Sm [20] were used as dopants in order to modify the ZnO magnetic properties.

In this paper, we have prepared undoped and Ho-doped $\mathrm{ZnO}$ thin films, using the sol-gel method. Holmium has the highest magnetic moment $\left(10 \mu_{\mathrm{B}}\right)$ of all naturally occurring elements and grants ferromagnetism below $19 \mathrm{~K}$ [27]. The influence of holmium in the $\mathrm{ZnO}$ host matrix on magnetic properties is relatively poor debated in literature [28-29]. Therefore, a special attention is devoted to the magnetic and electrical properties of these materials in this study. 


\section{Experimental part}

Sample preparation. The thin films were obtained using a precursor solution of $0.7 \mathrm{M}$ zinc acetate dihydrate (ZnAc) (Merck, 99,5\%) and holmium nitrate pentahydrate (Aldrich, 99,99\%) - 1, 3 and 5 at. \% Ho in $\mathrm{ZnO}$, in absolute ethanol (ETOH) (Alfa Aesar, 99\%). Monoethanolamine (MEA) (Alfa Aesar, 98\%) was added as a complexing agent, to increase the ZnAc dissolution rate in ethanol. The as-obtained solution was aged under stirring for about $15 \mathrm{~h}$. Fused quartz (Alfa Aesar) substrates were used for the thin films deposition. Prior to the deposition, the substrates were cleaned successively in ethanol / acetone / ethanol for 5 minutes each solvent in an ultrasonic bath. The coating solution was deposited on the substrates by spin-coating ( $3000 \mathrm{rpm} / 30 \mathrm{~s})$, using a VTC 100 spin-coater. The films were deposited in 3 layers and subsequently pre-heated at $300{ }^{\circ} \mathrm{C}$ for 2 minutes. The final thermal treatment was performed at $500{ }^{\circ} \mathrm{C}$ for $2 \mathrm{~h}$.

Sample characterization. The morphology and the thicknesses of the films were determined using a JEOL JSM 6700F scanning electron microscope (SEM).

The room temperature electric properties were carried out using an Ecopia Hall effect equipment. The Hall coefficient and the resistivity $(\rho)$ are experimentally determined and then related to the electrical parameters through the following relations (for the $n$-type conduction):

$$
\begin{aligned}
R_{H} & =\frac{r_{H}}{n \times \theta} \\
\mu_{H} & =\frac{r_{H}}{\rho}
\end{aligned}
$$

where $n$ is the free-electron concentration, $e$ is the unit electronic charge, $\mu_{H}$ is the Hall mobility, and $r_{H}$ is the Hall scattering factor which is dependent on the particular scattering mechanism. The transport properties reported in literature, mostly based on Hall effect measurements, assume the Hall scattering factor to be unity [30].

A MPMS SQUID-VSM (Quantum Design) magnetometer in a temperature and field ranges of 5 - $300 \mathrm{~K}$ and $0-7 \mathrm{~T}$, respectively, was used to determine the magnetic properties of the samples.

EPR measurements of the thin films were carried out on a Bruker E-500 ELEXSYS X-band spectrometer at room temperature. The spectra processing was performed by Bruker Xepr software.

\section{Results and discussion}

Morphological characterization. The SEM images are shown in Fig. 1. The films present an homogeneous morphology in undoped $\mathrm{ZnO}$ and 1 and 3 at. \% Ho-doped $\mathrm{ZnO}$. Small bumps in the Ho-doped $\mathrm{ZnO}$ thin films morphology can be observed. The thicknesses of the films vary between $200-250 \mathrm{~nm}$.

Electrical characterization. The resistivity and the Hall mobility as function of Ho doping is shown in Fig. 2. One can remark a small increase of the resistivity by increasing the holmium concentration from 0 to 5 at. \%. Seemingly, the enhancement is slightly accentuated in the 5 at. \% Ho-doped sample, as compared with the trend observed for the rest of the samples. S. Singh et al [28] have also reported the increase of the resistivity when doping the $\mathrm{ZnO}$ nanoparticles with Ho. The Hall mobility exhibits a decrease when the Ho concentration raised from 0 to 3 at. \% and further increased when the Ho concentration reaches 5 at. \%. These materials show a $n$-type conductivity, having a carrier concentration as high as $1.8 \times 10^{19} \mathrm{~cm}^{-3}$ for the undoped $\mathrm{ZnO}$, while the highest carrier concentration of the Ho-doped $\mathrm{ZnO}$ series was $3.2 \times 10^{19} \mathrm{~cm}^{-3}$ for the 3 at. \% Hodoped sample. 

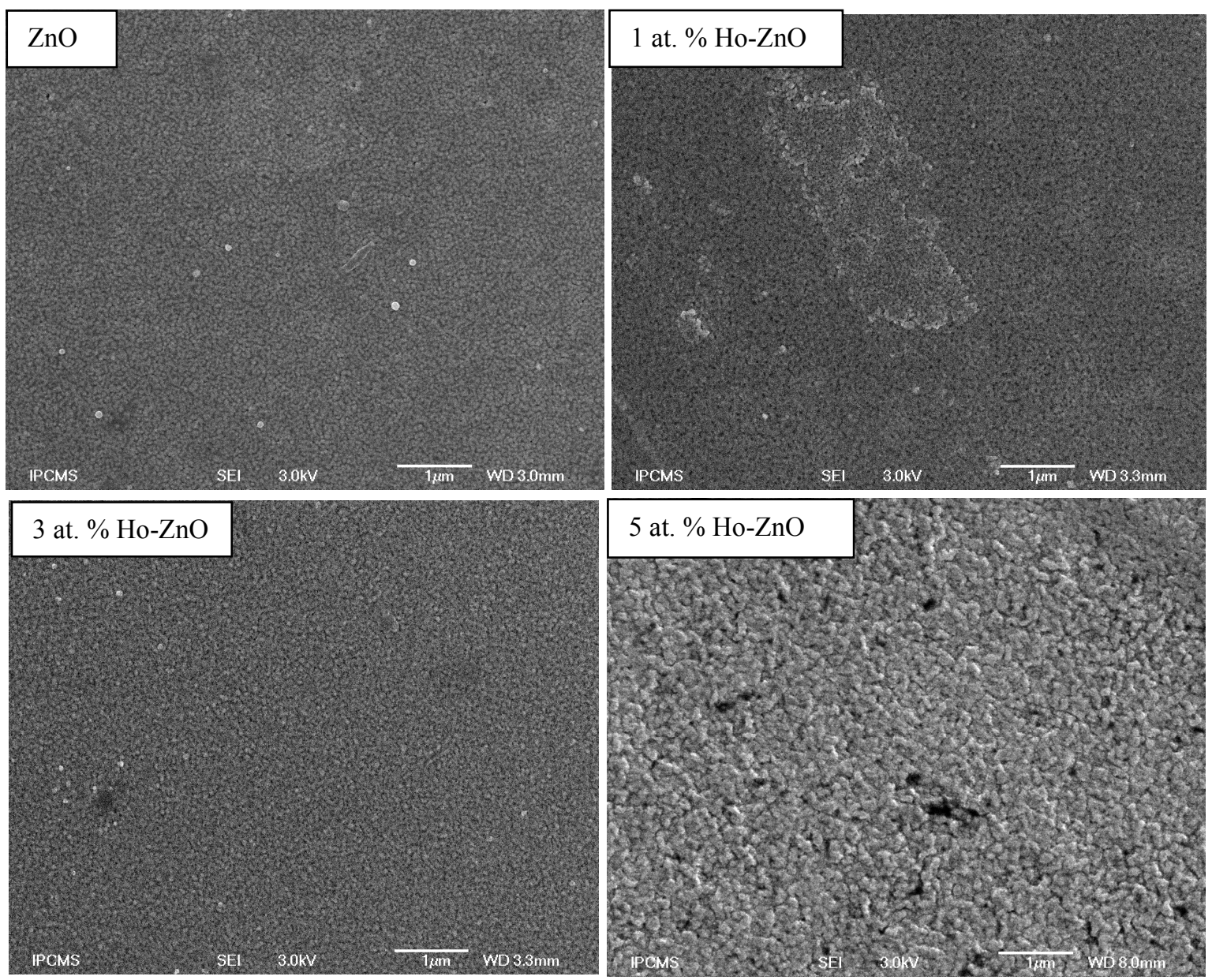

Fig. 1. SEM images of undoped and 1, 3 and 5 at. \% Ho-doped $\mathrm{ZnO}$ thin films.

Undoped $\mathrm{ZnO}$ with a wurtzite structure naturally is confirmed as an $n$-type semiconductor due to the presence of intrinsic or extrinsic defects, which were generally attributed to native defects, such as the $\mathrm{Zn}$-on-O antisite $(\mathrm{ZnO})$, the $\mathrm{Zn}$ interstitial $\left(\mathrm{Zn}_{\mathrm{i}}\right)$, and the $\mathrm{O}$ vacancy $\left(\mathrm{V}_{\mathrm{o}}\right)$ [30].

EPR spectroscopy is a sensitive technique to characterize paramagnetic centers, impurities, and other types of defects in any material. Fig. 3 presents the EPR spectra of $\mathrm{ZnO}$ and 5 at. \% Ho-doped $\mathrm{ZnO}$ thin films. The EPR spectrum corresponding to the $\mathrm{ZnO}$ thin films shows a low and broad signal centered at $\mathrm{g}=2.019$. In literature, this signal has been attributed to $\mathrm{Zn}$ vacancies [31]. For the 5 at. \% Ho-doped $\mathrm{ZnO}$ thin films, the EPR spectrum exhibits two sharp signals at $\mathrm{g}=2.14$ and $\mathrm{g}$ $=2.75$. The intense resonance at $g=2.14$ has been assigned to $\mathrm{Zn}$ vacancy [31-32]. The origin of the resonance at $\mathrm{g}=2.75$ is not known. As expected, no resonance signal corresponding to $\mathrm{Ho}^{3+}$ ions was observed at room temperature.

The electrical properties of the undoped $\mathrm{ZnO}$ thin films prepared by sol-gel are comparable with those reported in literature [33-35], while the Ho-doped $\mathrm{ZnO}$ resistivities seem to be higher than those of Sm-doped $\mathrm{ZnO}$ thin films, considering a thickness of about $200 \mathrm{~nm}$ [20]. In the undoped $\mathrm{ZnO}$, the trapped carriers in the grain boundaries could be responsable for the increase of the resistivity [34]. In the Ho-doped $\mathrm{ZnO}$ series, the insertion of the holmium ions in the $\mathrm{ZnO}$ matrix is expected to be rather difficult due to the higher ionic radius of the $\mathrm{Ho}^{3+}$ ions $(0.904 \AA)$ as compared with the $\mathrm{Zn}$ ionic radius $(0.704 \AA)$. The rare earths could be located at the $\mathrm{ZnO}$ grain boundaries, probably as oxides or as REZnO unknown compounds [36], increasing the number of surface defects in the $\mathrm{ZnO}$ matrix. Hence, the electrical resistivity of $\mathrm{ZnO}$ is reduced as the concentration of holmium in $\mathrm{ZnO}$ is increased. 


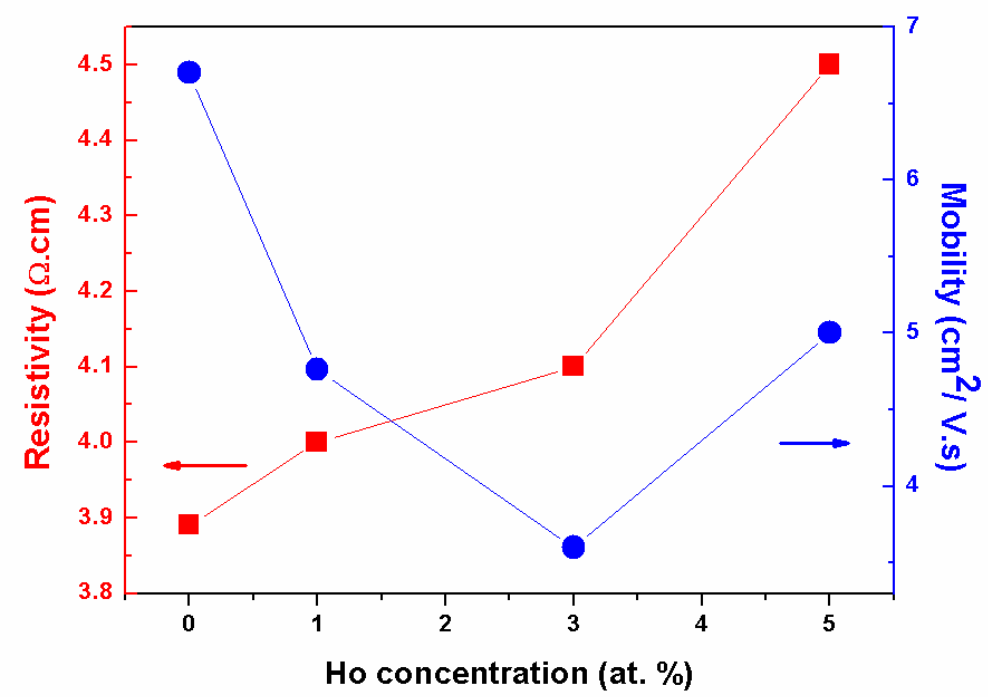

Fig. 2. Resistivity and Hall mobility dependences on Ho concentration in the $\mathrm{ZnO}$ thin films.

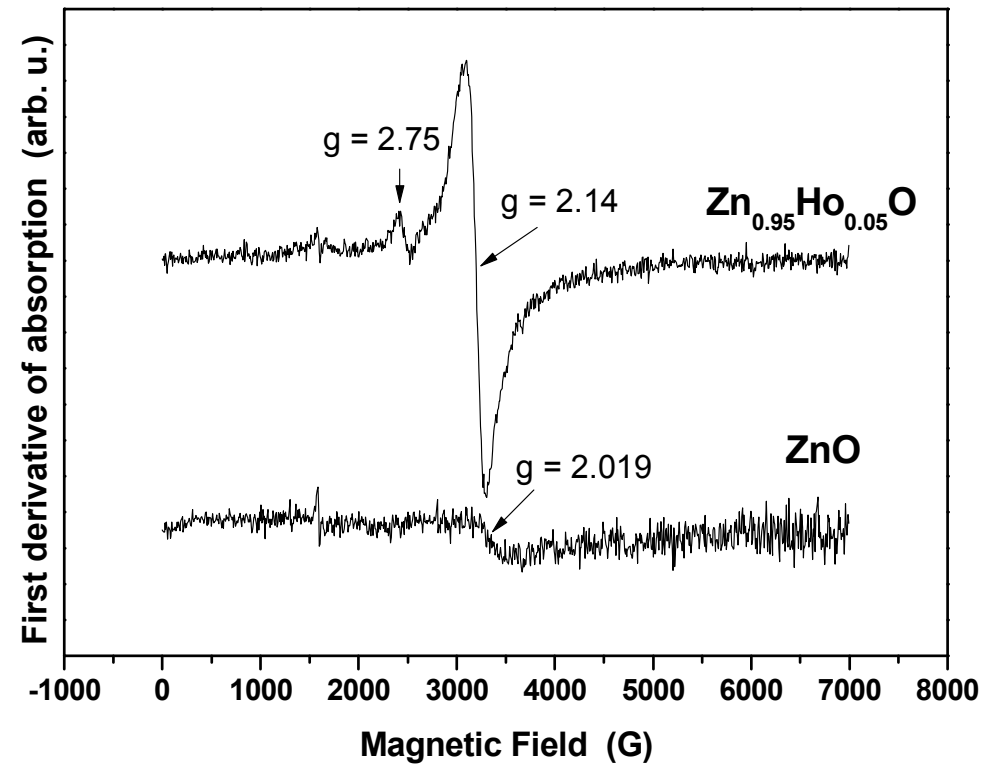

Fig. 3. EPR spectra of the as-deposited undoped and 5 at. \% Ho-doped $\mathrm{ZnO}$ thin films at room temperature.

Magnetic characterization. The magnetic properties of the samples have also been determined. As expected, the quartz substrate is diamagnetic in the temperature range $5-300 \mathrm{~K}$. After substracting the diamagnetic background arising from the substrate, a low paramagnetic behavior has been observed in the undoped $\mathrm{ZnO}$ thin films (not shown). The $\mathrm{M}(\mathrm{H})$ curves of the 5 at \% Hodoped $\mathrm{ZnO}$ thin film, measured at 5 and $300 \mathrm{~K}$, respectively, are shown in Fig. 4 a). A very weak hysteretic comportment can be observed at $5 \mathrm{~K}$. (inset Fig. 4 a)). Room temperature measurements reveal a small paramagnetic behavior, comparable with that of the undoped $\mathrm{ZnO}$ sample. The magnetic behavior at $5 \mathrm{~K}$ is however difficult to be customized. Rai et al [29] have observed a room temperature ferromagnetic behavior in the 5 at \% Ho-doped $\mathrm{ZnO}$ thin films, detecting a coercive field of $\mathrm{H}_{\mathrm{C}} \sim 54 \mathrm{Oe}$ and a saturation magnetization of 0.339 emu. However, Singh et al [28] have also reported a "S"-like hysteresis at $5 \mathrm{~K}$, in the Ho-doped $\mathrm{ZnO}$ nanoparticles, where the superparamagnetism below blocking temperature $\left(\mathrm{T}_{\mathrm{b}}\right.$ ) was not excluded (at $5 \mathrm{~K}, \mathrm{~T}_{\mathrm{b}}$ was not 
observed experimentally in our case). The ferromagnetism in Ho-doped $\mathrm{ZnO}$ was attributed to the substitution of $\mathrm{Zn}^{2+}$ with $\mathrm{Ho}^{3+}$ ions and was explained as a mediated exchange interaction between the $4 \mathrm{f} \mathrm{Ho}^{3+}$ ions (magnetic moment about $10 \mu_{\mathrm{B}}$ and $\mathrm{S}=2$ ) and the free delocalized carriers of the $5 d$ ions [29].

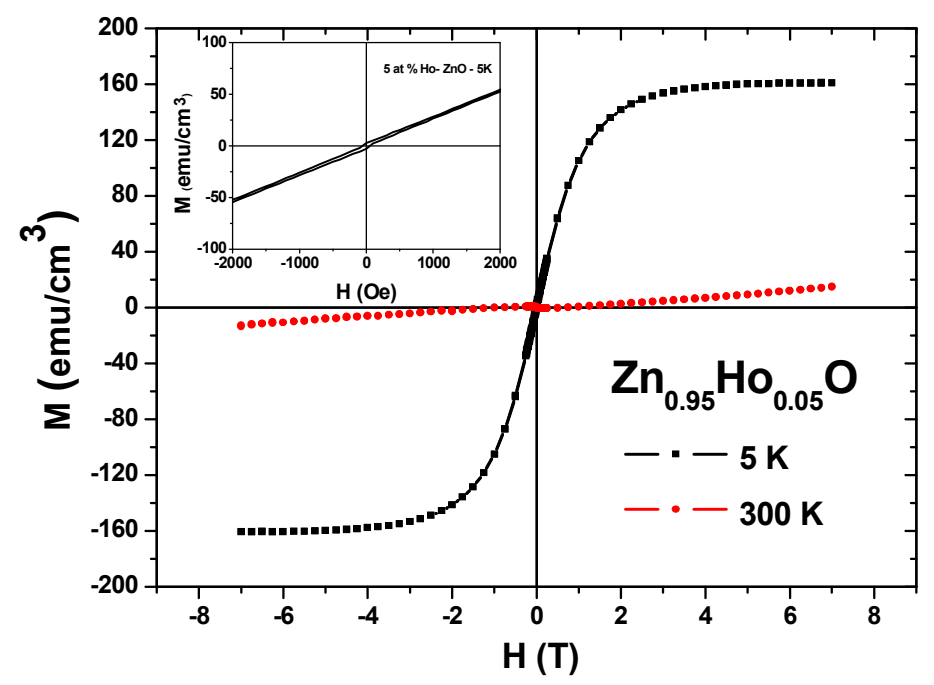

a)

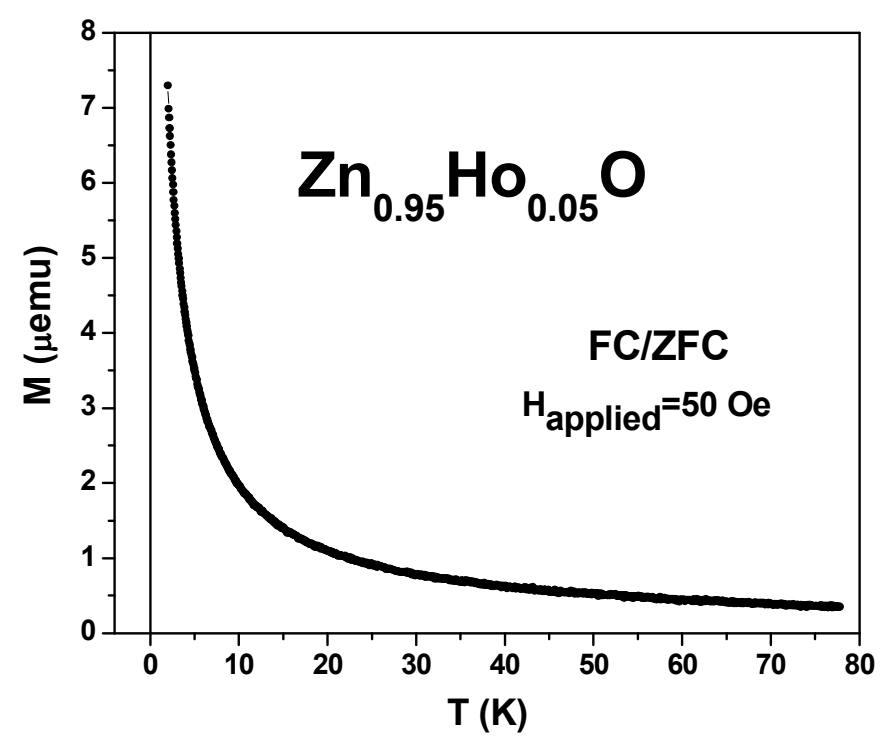

b)

Fig.4. a) Magnetization vs. magnetic field for the 5 at. \% Ho-doped $\mathrm{ZnO}$ thin film at 5 and $300 \mathrm{~K}$; in the inset, a zoom of the hysteresis recorded at $5 \mathrm{~K}$ (inset) and b) The field cooled (FC) and zero field cooled (ZFC) curves for the 5 at. \% Ho doped $\mathrm{ZnO}$ thin film.

The low hysteretic behavior observed at $5 \mathrm{~K}$ makes us believe that a weak ferromagnetic phase might exist in our samples. However, some small $\mathrm{Ho}_{2} \mathrm{O}_{3}-\mathrm{ZnO}$ heteroparticles or some individual $\mathrm{Ho}_{2} \mathrm{O}_{3}$ nanoparticles (more likely smaller than $10 \mathrm{~nm}$ ) are probably responsible of the rather paramagnetic behavior that we observed. The temperature dependence of the magnetic properties was investigated by zero field cooled - field cooled (ZFC-FC) measurement, performed by applying a magnetic field of $50 \mathrm{Oe}$ (Fig. 4 b). As can be seen, the ZFC and FC curves are overlapped, having a sharp decrease of the magnetization below $10 \mathrm{~K}$. The magnetization was furthermore reduced when the measurement temperature increased above $10 \mathrm{~K}$. A similar ZFC-FC pattern was observed by Subramanian et al [24] in Gd-doped $\mathrm{ZnO}$ thin films, except for the overlapping of the two curves 
which took place only at around $300 \mathrm{~K}$. The overlapping of the ZFC-FC curves was also observed by $\mathrm{W}$. Van den Heuvel et al [37] in $\mathrm{Er}_{0.3} \mathrm{~Pb}_{0.7} \mathrm{~F}_{2.3}$. In combination with other observed magnetic properties, the authors noticed that the investigated nanoparticles are not superparamagnetic but simply paramagnetic, i.e., described by independent dynamics of individual magnetic moments of $\mathrm{Er}^{3+}$ ions.

Obviously, the electric and magnetic behaviors of the Ho-doped $\mathrm{ZnO}$ compositions could be particularly related to how the Ho ions interact with the $\mathrm{ZnO}$ host matrix. Therefore, an extended study in this way is specially required.

\section{Conclusion}

Undoped and Ho-doped $\mathrm{ZnO}$ thin films were synthesized by the sol-gel method in order to determine their morphological, electrical and magnetic properties. The SEM images have revealed an uniform structure for the undoped and 1 and 3 at. \% holmium-doped $\mathrm{ZnO}$ thin films and a distinct structure for the 5 at. \% Ho-doped $\mathrm{ZnO}$. The electrical properties, as determined from the Hall effect measurements, indicate an increase of the resistivity by increasing the Ho concentration from 0 to 5 at. \%. The highest resistivity was of $4.5 \Omega \times \mathrm{cm}$, in the case of the 5 at. \% Ho-doped $\mathrm{ZnO}$. The Hall mobility decreased by doping with 1 and 3 at. \% Ho and increased again for the 5 at. $\%$ Ho doped $\mathrm{ZnO}$. The carrier concentration was about $3.2 \times 10^{19} \mathrm{~cm}^{-3}$ in the 3 at. \% Ho doped $\mathrm{ZnO}$ and of about $1.8 \times 10^{19} \mathrm{~cm}^{-3}$ in the undoped $\mathrm{ZnO}$. The presence of interstitial zinc in the undoped $\mathrm{ZnO}$ and zinc vacancies in the 5 at. \% Ho doped $\mathrm{ZnO}$ thin films was observed by EPR spectroscopy. The magnetic measurements performed on the 5 at. \% Ho doped $\mathrm{ZnO}$ thin films exhibited a rather paramagnetic behavior at $5 \mathrm{~K}$ and reduced paramagnetism at room temperature.

\section{Acknowledgements}

This paper was supported by the project "Development and support of multidisciplinary postdoctoral programs in major technical areas of national strategy of Research - Development Innovation" 4D-POSTDOC, contract $\mathrm{n}^{\circ}$. POSDRU/89/1.5/S/52603, project co-funded by the European Social Fund through Sectoral Operational Program Human Resources Development 2007-2013 (M. Popa). This work was also supported by CNCSIS-UEFISCU project, $\mathrm{n}^{\circ}$. PN II idei code 106/2010 (T. Petrisor). The authors are thankful to Dr. Ovidiu Ersen from the 'Institut de Physique et Chimie des Matériaux de Strasbourg' (IPCMS, France) for the help given to obtain the morphological and magnetic measurements.

\section{References}

[1] C. Klingshirn, ZnO: Material, Physics and Applications, Chem. Phys. Chem., 8 (2007) 782 803.

[2] M. Popa, M. Filip, M. Gabor, T. Petrisor Jr., L. Ciontea, T. Petrisor, Highly c-axis oriented ZnO thin film using 1-propanol as solvent in sol-gel synthesis, Mater. Lett., 92 (2013) 267-270.

[3] K. Sato, Material Design for Transparent Ferromagnets with ZnO-Based Magnetic Semiconductors, Jpn. J. Appl. Phys., 39 (2000) L555.

[4] R. M. I. Soumahoro, S. Colis, M. Ait Aouaj, M. Abd-lefdil, N. Hassanain, A. D. A. Berrada, Structural, optical, and magnetic properties of Fe-doped $\mathrm{ZnO}$ films prepared by spray pyrolysis method, Thin Solid Films, 518 (2010) 4593 - 4596.

[5] S. Maensiri, C. Thomas, J. Klinkaewnarong, Magnetic behavior of nanocrystalline powders of Co-doped $\mathrm{ZnO}$ diluted magnetic semiconductors synthesized by polymerizable precursor method, J. Magn. Magn. Mater., 301 (2006) 422-432.

[6] Y. Belghazi, S. Colis, J.L. Rehspringer, A. Berrada, A. Dinia, Room-temperature ferromagnetism in Co-doped $\mathrm{ZnO}$ thin films prepared by sol-gel method, J. Magn. Magn. Mater., 310 (2007) 2092-2094. 
[7] G. S. Chang, D. W. Boukhvalov, L. D. Finkelstein, A. Moewes, H. Bieber, S. Colis, A. Dinia, $\mathrm{Co}$ and $\mathrm{Al}$ co-doping for ferromagnetism in $\mathrm{ZnO}: \mathrm{Co}$ diluted magnetic semiconductors, J. Phys.: Condens. Matter., 21 ( 2009 ) 056002-056007.

[8] W. Chen, Y.Q. Wang, J.H. Miao, S. Liu, Z.C. Xia, S.L. Yuan, Magnetism in Mn-doped ZnO bulk samples, Solid State Commun., 134 (2005 ) 827-830.

[9] S. Kim, B.-T. Lee, Heteroepitaxial growth behavior of Mn-doped $\mathrm{ZnO}$ thin films on Al2O3 0001 by pulsed laser deposition, J. Appl. Phys., 95 (2004) 454-459.

[10] Y.-M. Hao, Sh.-M. Zhou, R.-J. Yuan, G.-Y. Zhu, N. Li, Structural, optical, and magnetic studies of manganese-doped zinc oxide hierarchical microspheres by self-assembly of nanoparticles, Nanoscale Res. Lett., 7 (2012) 1-9.

[11] T. Wakano, Y. Morinaga, N. Abe, A. Ashida, T. Ito, Magnetic and magneto-transport properties of $\mathrm{ZnO}$ : Ni films, Physica E 10 (2001) 260-264.

[12] S. J. Pearton, M. P. Ivill, A. F. Hebard, J. M. Zavada, W. M. Chen, I. A. Buyanova, ZnO Doped With Transition Metal Ions, IEEE Trans. Electron. Devices, 54 (2007) 1040-1048.

[13] N. Brihi, A. Berbadj, G. Schmerber, S. Colis, A. Dinia, No ferromagnetic properties in polycrystalline Al-doped $\mathrm{Zn}_{0.97} \mathrm{Mn}_{0.03} \mathrm{O}$ diluted magnetic semiconductor, Thin Solid Films, 518 (2010) 4549-4552.

[14] R. Lardé, P. Pareige, H. Bieber, G. Schmerber, S. Colis,V. Pierron-Bohnes, A. Dinia, Evidence of superparamagnetic Co clusters in pulsed laser deposition-grown $\mathrm{Zn}_{0.9} \mathrm{Co}_{0.1} \mathrm{O}$ thin films using atom probe tomography, J. Am. Chem. Soc., 133 (2011) 1451-1458.

[15] R. Escudero, Ferromagnetic behavior of high-purity $\mathrm{ZnO}$ nanoparticles, Solid State Commun., 151 (2011) 97-101.

[16] X. Ma, The magnetic properties of Gd doped ZnO nanowires, Thin Solid Films 520 (2012) 5752-5755.

[17] J. Qi, L. Zhang, J. Chi, D. Gao, D. Xue, Room-temperature ferromagnetism in Er-doped ZnO thin films, Scripta Mater., 60 (2009) 289-292.

[18] R. John, Synthesis and Characterization of Rare Earth Ion Doped Nano ZnO, Nano-Micro Lett. , 4 (2012) 65-72.

[19] S. Zhou, A. Mucklich, F. Eichhorn, M. Helm, W. Skorupa, J. Fassbender, Structural and magnetic properties of $\mathrm{Tb}$ implanted $\mathrm{ZnO}$ single crystals, Nucl. Instrum. Meth. Phys. Res. B, 266 (2008 ) 589-593.

[20] G. Murtaza Rai, Y.B.Xu, I.G.Will, Z.C. Huang, Study of Sm-doped ZnO samples sintered in a nitrogen atmosphere and deposited on $\mathrm{n}-\mathrm{Si}(100)$ by evaporation technique, J. Magn. Magn. Mater., 323 (2011) 3239-3245.

[21] R.A. Mereu, M. Vasilescu, M. Popa, M.S. Gabor, L. Ciontea, T. Petrisor, Synthesis and characterization of undoped, $\mathrm{Al}$ and/or $\mathrm{Ho}$ doped $\mathrm{ZnO}$ Thin Films, Ceram. Int., http://dx.doi.org/10.1016/j.ceramint.2012.12.067 (2013).

[22] A. A. Dakhel, Ferromagnetic nanocrystalline Gd-doped $\mathrm{ZnO}$ powder synthesized by coprecipitation, J. Appl. Phys., 107 (2010) 123901-123906.

[23] V. Ney, T. Kammermeier, K. Ollefs, F. Wilhelm, A. Rogalev, S. Lebègue, A. L. da Rosa, A. Ney, Structural and magnetic analysis of epitaxial films of Gd-doped ZnO, Phys. Rev. B, 85 (2012) 235201-235207.

[24] M. Subramanian, M. Tanemura, T. Hihara, V. Ganesan, T. Soga, K. H. Chae, R. Jayavel, T. Jimbo, Intrinsic ferromagnetism and magnetic anisotropy in Gd-doped $\mathrm{ZnO}$ thin films synthesized by pulsed spray pyrolysis method, J. Appl. Phys., 108 (2010) 053901-053907.

[25] Z. Wu, J. C. A. Huang, Room temperature ferromagnetism in Tb doped $\mathrm{ZnO}$ nanocrystalline films, J. Magn. Magn. Mater., 324 (2011) 642-644.

[26] T. Yong-Sheng, Chen Wei,He Pi-Mo, Ferromagnetism in Eu-doped ZnO films deposited by radio-frequency magnetic sputtering, Chin. Phys. B, 19 (2010) 097501-097504.

[27] D. Jiles, Introduction to magnetism and magnetic materials, in: Ed. (Ed.), Chapman \& Hall, 1998. 
[28] S. Singh, B. Ramachandran, M.S. Ramachandra Rao, Synthesis and comparative study of Ho and Y doped ZnO nanoparticles, Mater. Lett., 65 (2011) 2930-2933.

[29] G. M. Rai, Y. Xu, I. G. Will, W. Zhang, Influence of Rare Earth Ho3+ Doping on Structural, Microstructure and Magnetic Properties of ZnO Bulk and Thin Film Systems, Chin. J. Chem. Phys., 24 (2011) 353-357.

[30] Ü. Özgür, C. Liu, A. Teke, M. A. Reshchikov, S. Doğan, V. Avrutin, S.-J. Cho, H. Morkoç, A comprehensive review of ZnO materials and devices, J. Appl. Phys. , 98 (2005) 041301-041103.

[31] R. P. S. Chakradhar, J. L. Rao, B. J. Basu, Fabrication of superhydrophobic surfaces based on ZnO-PDMS nanocomposite coatings and study of its wetting behaviour, Appl. Surf. Sci., 257 (2011) 8569- 8575.

[32] A. Jagannatha Reddya, H. Nagabhushanac, J. L. Raod, C. Shivakumarae, B. M. Nagabhushanaf, R.P.S. Chakradharg EPR, thermo and photoluminescence properties of $\mathrm{ZnO}$ nanopowders, Spectrochim. Acta Part A, 81 (2011) 59- 63.

[33] R. Ghosh, D. Basak, Effect of thermal annealing treatment on structural, electrical and optical properties of transparent sol-gel ZnO thin films, Mater. Res. Bull., 40 (2005) 1905-1914.

[34] S. S. Shariffudi, S. H. Herman, M. Rusop, Effect of film thickness on structural, electrical, and optical properties of sol-gel deposited layer-by-layer $\mathrm{ZnO}$ nanoparticles, Trans. Electr. Electron. Mater, 13 (2012) 102-105.

[35] J.-H. Lee, B.-O. Park, Electrical and optical properties of $\mathrm{ZnO}$ transparent conducting films by the sol-gel method, J. Cryst. Growth 247 (2003) 119-125.

[36] N. Jiang, J. Qiu, Electron energy-loss spectroscopy study of Yb doped ZnO, J. Appl. Phys., 108 (2010) 083531-083534.

[37] W. Van den Heuvel, D. Kirilenko, N. Schildermans, L. F. Chibotaru, J. Vanacken, P. Gredin, M. Mortier, G. van Tendeloo, V. V. Moshchalkov, Ultralow blocking temperature and breakdown of the giant spin model in Er3+-doped nanoparticles, Phys. Rev. B 82 (2010) 094421094428. 